\title{
HISTÓRIAS DE VIDA - MÃE E FILHO SOROPOSITIVO PARA O HIV
}

\author{
Mariana Vieira1, Maria Itayra Padilha², Evanguelia Kotzias Atherino dos Santos ${ }^{3}$
}

\footnotetext{
${ }^{1}$ Mestre em Enfermagem. Enfermeira da Secretaria de Estado da Administração de Santa Catarina. Santa Catarina. Brasil. E-mail:nanyufsc@ibest.com.br

${ }^{2}$ Doutora em Enfermagem. Professor Associado do Departamento de Enfermagem da Universidade Federal de Santa Catarina (UFSC). Pesquisadora do CNPq. Santa Catarina. Brasil. E-mail: padilha@nfr.ufsc.br

${ }^{3}$ Doutora em Enfermagem. Professor Associado do Departamento de Enfermagem da UFSC. Santa Catarina, Brasil. E-mail: gregos@matrix.com.br
}

\begin{abstract}
RESUMO: O objetivo foi identificar nas histórias de vida das mães, as estratégias desenvolvidas para conviver com o HIV e com a criança soropositivo para o HIV. Utilizou abordagem qualitativa e teve como método de coleta a História de Vida. Os sujeitos foram três mães HIV positivo no contexto de um Hospital-dia em Florianópolis-SC. A partir da análise temática de Bardin emergiram três categorias: memórias da infância; adolescência e maturidade. Os resultados enfocam estratégias desenvolvidas pelas mães para conviver com HIV, dentre estas, apoio familiar, religioso, prevenção, assim como, as estratégias das mesmas no convívio com a criança também com HIV, das quais temos, tratamento medicamentoso; revelação do diagnóstico à criança; cuidados diários, entre outros. Concluímos que tais estratégias desenvolvidas/adaptadas pelas mães no convívio com o HIV em si e na criança foram influenciadas pela sua cultura e experiências ao longo da sua história de vida.
\end{abstract}

DESCRITORES: HIV. Relações mãe-filho. Enfermagem. História.

\section{LIFE HISTORIES - HIV POSITIVE MOTHER AND SON}

\begin{abstract}
The objective of this study was to identify strategies of living with HIV in the life histories of HIV-positive mothers and children. It uses the qualitative approach and the Life History as a source of data collection. The subjects were three HIV-positive mothers within the context of a Day-Hospital in Florianópolis - SC - Brazil. Based on the Bardin's thematic analysis, three categories emerged: childhood, adolescence, and maturity memories. The results pointed out strategies developed by the mothers for living with HIV, among which were family, religious, prevention, and support. It also pointed out strategies developed for living with an HIV-positive child, such as as medical treatment, revealing the diagnosis to the child, daily care, and others. We concluded that these strategies developed/adapted by the mothers in living with HIV itself and the child were influenced by their cultures and experiences throughout their life history.
\end{abstract}

DESCRIPTORS: HIV. Mother child-relations. Nursing. History.

\section{HISTORIAS DE VIDA - MADRE E HIJO SEROPOSITIVOS PARA EL VIH}

RESUMEN: El objetivo del estudio fue identificar en las historias de vida de las madres, las estrategias desarrolladas para convivir con el VIH, y con el niño seropositivo para el VIH. Se utilizó el abordaje cualitativo, y el método para la recolección de datos fue la Historia de Vida. Los sujetos fueron tres madres con VIH positivo. Los sujetos fueron tres madres con VIH positivo, en el contexto de un Hospital-Día en Florianópolis-SC. Se utilizó el análisis temático de Bardin, del cual emergieron tres categorías: memorias de la infancia, adolescencia, y madurez. Los resultados focalizan las estrategias desarrolladas por las madres para convivir con VIH: apoyo familiar, religioso, prevención, así como, las estrategias de las mismas en su convivencia con el niño con VIH: tratamiento medicamentoso; revelación del diagnóstico al niño; cuidados diarios, entre otras. Concluimos que tales estrategias desarrolladas/ adaptadas por las madres en su convivencia con el VIH, en sí mismas y en el niño, fueron influenciadas por su cultura y por sus experiencias a lo largo de su historia de vida.

DESCRIPTORES: VHI. Relaciones madre-hijo. Enfermería. Historia. 


\section{INTRODUÇÃO}

É importante reforçar que, no decorrer dos anos, o padrão de transmissão do HIV no Brasil e no mundo vem mudando e atualmente não está mais associado a grupos de risco. Uma prova deste fato de acordo com os indicadores epidemiológicos, está no aumento dos números de casos de pessoas infectadas pelo HIV e Aids, relacionado à exposição heterossexual e com isto, uma proporção também cada vez maior de mulheres são atingidas. ${ }^{1}$

Em decorrência do aumento da vulnerabilidade feminina e, deste modo, também de crianças para a epidemia, o sistema familiar torna-se o alvo principal para a transmissão do HIV, determinando nos seus integrantes sentimentos de ameaças e discriminação, perante a sociedade. Seguindo esta linha de pensamento, identificamos a mãe soropositiva para o HIV como uma indispensável unidade cuidadora da criança também HIV soropositiva que, necessita por sua vez, também ser cuidada.

A opção por desenvolver este estudo com mães soropositivo para o HIV, que convivem com a criança também soropositivo para o HIV, orientando-nos pelas suas histórias de vida, é por acreditarmos que tais histórias influenciam nas estratégias/adaptações desenvolvidas pelas mães para conviver com a doença. Apesar do estudo ter sido realizado apenas com as mães, optamos em apresentar o conceito de família que norteou o trabalho, considerando que na maioria das famílias a mãe é o personagem principal da relação familiar. Assim, adotamos o conceito proposto pelo Grupo de Assistência, Pesquisa e Educação na área da Família (GAPEFAM - Universidade Federal de Santa Catarina) no qual a família é considerada uma unidade dinâmica constituída por pessoas que se percebem como família, que convivem por determinado espaço, com uma estrutura e organização para atingir objetivos comuns, construindo uma história de vida. Os membros da família estão unidos por laços consangüíneos, de adoção, interesse e/ou afetividade. Definem objetivos e promovem meios para o crescimento e desenvolvimento contínuo do seu processo de viver. $^{2}$ A mãe soropositivo para o HIV que convive com a criança também com esta condição é uma unidade de cuidado e fonte de ajuda para este ser criança, contribuindo para o seu bem estar e o seu estar melhor. Entendemos ainda que a mãe, frente à situação, está sujeita a enfrentar divergências entre os integrantes, contudo, os vínculos podem superar e confortar as dificuldades. Uma vez que serão estes mesmos vínculos que auxiliarão as mães a enfrentar a problematização frente ao diagnóstico da criança com tal condição.

Assim, entendemos que é de grande relevância estudar, conhecer o passado das mães para melhor compreendermos seus modos de viver hoje, suas estratégias desenvolvidas no convívio com a doença em si e na criança, e assim de certa forma poder ajudá-las. Logo o estudo tem como objetivo - Identificar nas histórias de vida das mães as estratégias desenvolvidas pelas mesmas para conviverem com o HIV, assim como, com a criança na mesma condição.

\section{METODOLOGIA}

Trata-se de uma pesquisa qualitativa cujo contexto foi um Hospital Dia (HD), localizado em Florianópolis-SC, que atende crianças HIV positivas de todo o Estado de Santa Catarina. Adotamos como sujeitos um quantitativo de três mães soropositivas para o HIV, as quais foram consideradas suficientes a partir da saturação dos dados. As mães foram selecionadas de acordo com os seguintes critérios de inclusão: mães biológicas soropositivo para o HIV, que convivem com a criança também HIV positivo e que aceitaram participar do estudo. Estas mães residem em bairros da Grande Florianópolis. Aos sujeitos do estudo tomamos emprestado o nome de "anjos" como codinome por acreditarmos que todos ao longo de sua história de vida têm um protetor, um anjo guardião.

A coleta de dados se deu pela História de Vida das mães, considerando que esta é uma fonte histórica que investiga o que ocorreu em um tempo recente, sendo possível identificar as pessoas que vivenciaram e participaram do processo histórico, a fim de integrá-las à pesquisa. ${ }^{3}$ Foi utilizado um roteiro de entrevista semi-estruturado com 20 questões a respeito da história de vida das mães e foram realizadas duas entrevistas com cada sujeito do estudo, totalizando cerca de 120 minutos cada. Uma segunda entrevista foi necessária, a fim de que se pudesse aprofundar as informações e completar as lacunas deixadas na primeira entrevista. Além disso, a História de Vida implica em um processo lento e gradual das informações. A coleta de dados ocorreu no período de março a junho de 2007 no ambulatório do HD. Ressaltamos que para a identificação e compreensão de tais estratégias foi necessário o estabelecimento do vínculo junto às mães, compromisso este estabelecido mediante o diálogo e a interação, conquistados aos poucos, desde o primeiro encontro/entrevista com as mães. 
Quanto ao processo de registro e análise dos dados, as entrevistas foram gravadas com a anuência dos entrevistados e posteriormente, transcritas. Optamos pela análise temática, pois esta é geralmente utilizada como unidade de registro para estudar motivações de opiniões, de atitudes, de valores, de tendências. ${ }^{4}$ Para a realização da análise, inicialmente realizamos a leitura detalhada das entrevistas a fim de levantar as unidades de registro que mais se evidenciaram nos depoimentos para, a partir daí, identificar e selecionar os dados mais relevantes e chegar as categorias de análise. Foram estabelecidas as seguintes categorias - Memórias da infância, Memórias da adolescência, Memórias da maturidade com suas respectivas subcategorias. A respeito dos componentes éticos, de acordo com a Resolução N ${ }^{0} 196 / 96,{ }^{5}$ a pesquisa foi submetida e aprovada pelo Comitê de Ética em Pesquisa com Seres Humanos da Universidade Federal de Santa Catarina, através do parecer consubstanciado de $\mathrm{N}^{\mathrm{o}} 012 / 2006$ e registro no CEP de número $\mathrm{N}^{\circ}$ 015/2006. E a fim de respeitar e assegurar o anonimato dos sujeito, estes assinaram o Termo de Consentimento Livre e Esclarecido.

\section{RESULTADOS E DISCUSSÃO}

\section{As memórias da infância e adolescência}

A inserção da mulher no mercado de trabalho tem mudado a característica de "família grande", quando comparada às gerações anteriores, mas ainda é freqüiente encontrarmos este tipo de família com baixa renda e classe sócio-econômica pobre. ${ }^{6}$ É o caso de Mikael que teve três relacionamentos conjugais e destes concebeu seis filhos.

...com 17 anos casei e tive três filhos, duas meninas e um menino. [...] como ele não quis assumir o nosso terceiro filho e não queria nada com nada, achei melhor separar. [...] quando meus três filhos eram pequenos conheci com 26 anos, o meu segundo marido, pai do meu quarto filho. Esse meu relacionamento também foi outro, que não durou nada... ele era mulherengo, só queria folia. Agora tô casada com meu terceiro marido, o que eu vivo hoje, pai das minhas duas filhas mais novas. Meu Deus agora chega de filhos! (Mikael).

A mãe ao longo de sua história vive momentos de alegria e tristeza, esperança e desesperança, algumas se estruturam outras se desestruturam e vários são os fatores para tais acontecimentos. Uma das maiores causas para tal desestruturação familiar está no uso das drogas ilícitas e até mesmo as lícitas, quando estas últimas são utilizadas de forma indiscriminada. ${ }^{7}$ Episódio que pode ser evidenciado, a partir de relatos de Mikael e Ariel ao referirem sobre o uso do álcool pelos seus pais, acarretando na agressividade dos mesmos com sua família.

Quando eu era pequena, a minha família se dava muito bem... mas depois que ele se meteu na bebida, começou dai a desgraça... usava drogas, arranjava mulher na rua...é eu lembro de alguma coisa, porque era a filha mais velha. [...] Acho que por isso me dava melhor com minha mãe do que com meu pai, ele a té que era bom pra mim e pras minhas irmãs também, mas infelizmente com a minha mãe, ui, credo, coitada... quando bebia, ele se transformava num bicho (Mikael).

[...] Não dá pra acreditar, meu pai que vivia todo sério, certinho começou a sair escondido para bailão, dai voltava bêbado para casa, achando que tava com a razão... o pior é que ficava agressivo com minha mãe e as vezes até comigo, com meus irmãos (Ariel).

É visível o poder estruturante do dinamismo patriarcal, onde o pai na maioria das vezes faz o papel de senhor absoluto da esposa e filhos, tendo com estes uma relação muito mais próxima ao terror que ao amor e respeito. Esta situação atualmente é questionada tanto pelos filhos, como pela mulher, os quais na maioria das vezes assumiam o papel de submissão na relação. Mas que felizmente hoje é questionada tanto pelos filhos, como pela mulher, os quais na maioria das vezes assumiam o papel de submissão na relação. ${ }^{6}$ Isto pode ser evidenciado na seguinte fala.

Meu primeiro casamento durou seis anos, até meus 23 anos, mas não agüentei... começou a beber, usar droga, proibia eu de trabalhar... ah! Não, não queria isso pra mim também, já não basta o que sofri vendo a minha mãe sofrer, sabe (Mikael).

Quanto ao convívio extrafamiliar dos sujeitos do estudo durante a infância e, especialmente, na escola é pautado por problemas familiares, dificuldades socioeconômicas por não puderem dar continuidade aos seus estudos.

Quando eu tava com 11 anos, tive que parar de estudar... meus pais se separam. Minha mãe começou a trabalhar pra arranjar dinheiro e eu por se a mais velha sai também de casa, trabalhei de babá dos 12 anos até os 15. [...] o dinheiro que ganhava entregava pra minha mãe. Só tinha abandonado a escola porque tinha que ajudar minha família (Mikael).

Meu pai faleceu de câncer no estômago, quando eu tava com nove anos, daí minha mãe começou a passar dificuldade. Então dos nove aos 13 anos morei com uma senhora idosa que era mãe da minha professora... lá eu 
fazia companhia pra ela, limpava a casa, arrumava a cozinha. [...] Dai acabei parando os estudos e comecei a trabalhar de doméstica (Aladiah).

Nas classes com baixa renda há necessidade de que os filhos se tornem independentes precocemente, a fim de fazer parte da força de trabalho e contribuir economicamente com as despesas da família. E, esta independência de certa maneira, constitui uma carga menor para os pais, além disso, a carga de responsabilidade que é imputada aos filhos, faz muitas vezes com que os mesmos interrompam o seu processo de educação formal e procurem empregos assalariados, tornando mais difícil ainda a sua inserção no sistema social. ${ }^{8}$

No presente estudo foi abordado também o período da adolescência das mães, sujeitos do estudo, enfocando os relacionamentos e as questões vinculadas ao corpo, à sexualidade, dos quais foi caracterizado pela ausência de diálogo com a família.

Acho muito importante os pais conversarem sobre o corpo com a criança e com o adolescente, claro que tudo no seu tempo, mas é preciso conversar, mostrar o que é certo e o que é errado. (...) Lá em casa eu tenho o jogo aberto com meus filhos, converso muito com eles pra se cuidarem, pra não acontecer com eles, o que aconteceu com a mãe (Mikael).

Sabe aquela conversa que a mãe tem com a menina sobre o corpo, como se cuidar... então eu nunca tive com minha mãe. É eu tenho a cabeça aberta que vou precisar conversar com meu filho sobre estes assuntos (Aladiah).

Em tempos de HIV/Aids, todos devem ser considerar vulneráveis, independente da raça, idade e religião. Neste sentido pensamos ser de extrema importância o diálogo dos pais, assim como, a abordagem da escola sobre assuntos que envolvem a sexualidade, pois as pessoas no decorrer da sua vida, principalmente na fase da adolescência, caracterizam-se por serem curiosas, que se verem isentos de riscos. ${ }^{9}$ Felizmente, neste contexto há de salientar as mudanças de comportamentos/condutas por parte de Mikael e Aladiah, que ao contrário de seus pais para consigo na adolescência, passam a conversar, dialogar com seus filhos sobre sua sexualidade.

\section{As memórias da maturidade}

Esta categoria trata da memória das mães sobre o seu passado e, mais especialmente, a partir do diagnóstico positivo para o HIV. O objetivo desta categoria é apresentar os modos pelos quais as mães desenvolvem estratégias para conviver com esta condição e também cuidar de modo mais adequado de seu filho também HIV positivo.

A descoberta da infecção pelo HIV ocorre, nos mais diversificados momentos da vida das pessoas. ${ }^{10}$ Neste estudo, esta se deu em momentos inesperados, como o nascimento de um filho ou diagnóstico de outra doença.

Quando meu filho tava com menos de 14 dias, tive uma notícia péssima, fiquei muito triste, chorava muito... ele teve que ficar internado urgentemente por pneumonia na Unidade de Terapia Intensiva, lá em Lajes mesmo onde eu morava e para piorar acabou sendo transportado pra Unidade de Terapia Intensiva do Hospital Infantil, aqui em Florianópolis. Neste hospital pediram vários exames, até o de Aids e então veio o resultado positivo do HIV... daí foi feito em mim e no meu marido e todos deram positivos. [...] Chorava muito pelos corredores daquele hospital... só pensava em me matar, me jogar de uma ponte pra minha vida acabar de uma vez (Aladiah).

Descobri há seis anos, quando minha filha estava com dois aninhos, fui fazer o exame preventivo de rotina e deu alterado... estava com câncer... fiquei muito mal. [...] Daí fui encaminhada para um hospital, fiz vários exames, até o de Aids. É parece que tô vendo hoje, quando a médica disse o resultado! Acho que foi assim uma facada no peito, chorei tanto... me apavorei, me desesperei.[...] Meu Deus! Agora tô morta, achava que tava morta, porque com câncer, HIV, e como é que vou cuidar de meus filhos? (Mikael).

O enfrentamento da doença e a incorporação da mesma ao processo de viver são questões que normalmente geram ansiedade e sofrimento, principalmente nas pessoas ao descobrirem sua soropositividade. O impacto da revelação do diagnóstico de soropositividade para o HIV é percebido de diferentes modos para cada uma delas e a maneira de reagir face à descoberta é influenciada de acordo com diferentes fatores. ${ }^{7,11}$

Contudo enfatizamos que o significado que cada mãe dá para a descoberta de sua condição de HIV positivo difere entre si, sendo determinado pelo contexto em que viveu e que vive hoje, pelas suas experiências, valores, pela sua história de vida e estrutura interna de cada um, assim como pelo grupo social em que está inserida.

Algumas mães não conversam a respeito do HIV/Aids, por se considerarem invulneráveis, com a idéia de que a doença só acontece nas outras famílias, fato que pode estar associado à concepção da mesma ser visto como uma doença de caráter moral e social que envolve dois grandes tabus da 
sociedade, o sexo e a morte. A falta de informações sobre a infecção pelo HIV, sobre a maneira de contaminação, os aspectos biológicos, culturais, psicológicos e sociais que envolvem a problemática de tal infecção, assim como o estigma e o preconceito justificam a importância do esclarecimento sobre o mesmo, de sua situação atual no mundo, dos avanços e das possibilidades de tratamento. ${ }^{12}$

No caso de Mikael o interesse pela temática foi inevitável, pois com a descoberta da sua condição sorológica para o HIV percebeu que não tinha conhecimento sobre a infecção. Ou pior, o pouco que sabia estava impregnado de discriminação, mitos, decorrente das falsas informações. Quanto a Aladiah, o interesse pelo assunto sempre esteve presente em sua vida, no entanto, não tão marcante como após o diagnóstico em si e no seu filho. Aladiah, desde criança, sempre se mostrou uma menina muito curiosa e interessada em aprender, muitas das vezes tal conhecimento acontecia por si, principalmente quando o assunto envolvia sexo, corpo, drogas, HIV/ Aids, visto que os mesmos não eram dialogados entre os membros da sua família.

Algumas estratégias relatadas pelos sujeitos deste estudo no convívio com o HIV foram: apoio familiar, religioso, tratamento medicamentoso, o cuidado para com a família (esposo, filhos), aspectos relacionados à prevenção, bem como as condutas dos sujeitos frente a atitudes de discriminação. Em relação ao apoio familiar, as três mães ressaltaram a importância da família, no processo de convívio com tal ssssituação.

No início minha mãe não acreditava, só chorava. [...] mas depois ela e meus irmãos conversavam comigo pra eu não desanimar, ter fé. Este apoio da família vejo que foi o mais importante, porque tava grávida, recém casada e com HIV (Ariel).

[...] o HIV na minha vida e de minha família veio para trazer não só coisas ruins, mas também união. Com o apoio da família vi que o HIV não era o fim (Mikael).

[...] quando descobri que estávamos com HIV, liguei para minha irmã mais velha pra contar... foi difícil, não sabia como começar. Mas minha irmã pelo telefone me deu muito apoio, pedia pra mim parar de chorar, dizia 'seja forte mana, como foi desde pequena'. Daí eu pedi pra ela contar para o pessoal ai de casa... pra fazer uma reuniãozinha com a família, como o pai fazia quando a gente era pequeno, pra contar algum acontecimento (Aladiah).

Este último depoimento salienta a preocupação, o medo de como e quando revelar para seus familiares a sua situação sorológica positivo. A reunião para revelação do HIV, não deixa de ser uma estratégia escolhida por Aladiah e que foi influenciada pela sua história de vida, quando criança, uma vez que na presença de algum acontecimento bom ou ruim, o pai de Aladiah reunia a família.

Além do apoio familiar há também a influência da religião, da fé como estratégia para conviver com o HIV, representado a partir da fala.

[...] Eu e a minha mãe depois de ter recebido a notícia de que eu tinha HIV saímos abraçadas chorando e entramos numa igreja. Lá ouvi uma palavra de Deus que foi muito boa sabe. Eu me apeguei a Deusé ele que me dá força, coragem pra enfrentar os problemas (Mikael).

O comportamento do indivíduo é guiado por significados simbólicos e fatores como religião, fé, cultura, educação e rede social que influenciam na decisão por determinados recursos de saúde. ${ }^{13}$

Há ainda a importância da ajuda biomédica, com os tratamentos medicamentosos utilizados como recursos à saúde, recursos estes que podem ser representados pelas falas a seguir.

No início, passava uns dias sem tomar os remédios, não aceitava o que estava acontecendo comigo, negava, mas vi que tava ficando pior, magra, feia, fraca, daí vi que o remédio era necessário também. [...] Apesar de hoje estar aprendendo a me adaptar, a viver com o HIV, não vou mentir que aceito, só não me entrego a ele (Mikael).

No início, quando descobri o HIV, tomava os medicamentos tudo certinho, até porque tava grávida, mas depois de parir comecei a me relaxar sabe (Ariel).

Eu tomo os remédios do HIV até hoje, faço o tratamento bem certinho, todos os dias e no mesmo horário. Chego a colocar o relógio pra despertar pro meu remédio e também do meu filho. É preciso né, aquelas pessoas não têm que tomar aqueles remédios pra pressão, diabetes... todo dia? Então nós também (Aladiah).

Estas falas demonstram a importância da adesão aos medicamentos Anti-retrovirais (ARV), uma vez que a adesão aos mesmos faz aumentar a longevidade do indivíduo soropositivo para o HIV. Neste estímulo à adesão ao tratamento medicamentoso com ARV vale ressaltar a importância dos profissionais da saúde, em especial da enfermagem, que seja por tratamento ambulatorial ou hospitalar, é uma categoria que quase sempre, encontra-se presente, e tem a possibilidade de fazer parte da história de vida dos indivíduos que convivem com a infecção pelo HIV.${ }^{14}$ Ainda em relação ao tratamento medicamentoso, entre os familiares da mãe, relata-se. 
Meu marido diz que não precisa destas coisas, diz que não tem nada, daí não faz o tratamento, eu respeito né. Graças a Deus ele não tem ficado doente... Deus tem ajudado ele (Mikael).

O que me dá ânimo pra continuar o tratamento é minha família, meus filhos (Ariel).

Meus exames e de meu filho de carga viral sempre dão bom, já do meu marido não sei, porque é muito difícil ele fazer os exames e de tomar os remédios. [...] o homem é mais frágil pra doença né, não toma os remédios direito, custou mais pra 'aceitar' o HIV. [...] por mais que eu fiquei desesperada, lutei muito pra não me deixar abater, porque tenho meu filho e meu marido pra cuidar (Aladiah).

Tal preocupação abordada sobre o cuidado da mãe à criança, é influenciado pelo seu passado, pelas suas vivências/experiências, onde a figura materna no cuidado a estes sujeitos, quando criança, foi também muito marcante.

Em relação às estratégias das mães para conviver com a criança soropositivo para o HIV, as questões do roteiro de entrevista abordaram temas acerca do tratamento medicamentoso; não superproteção da criança; a presença do carinho, amor; contar ou não para a criança a sua condição de soropositividade para o HIV, bem como hábitos de vida, alimentação, educação, lazer, entre outras.

Cabe enfatizar ainda, que em todos os momentos, os sujeitos deixaram claro que a sua estratégia no convívio com a criança soropositivo para o HIV é a importância da não super-proteção no cuidado prestado à criança, a qual demonstramos a partir desta fala.

Cuido do meu filho como uma criança normal, não sou super protetora não, só gosto é de dar atenção, até porque ele é meu único filho. Nada que eu fiz para meu filho até hoje me arrependo, pelo contrário acho que devo fazer até mais, porque ele não tem culpa, não foi ele que escolheu ter HIV (Aladiah).

Apesar de falarem que não superprotegem seus filhos não é o que observamos neste estudo. Acreditamos que as ações/reações por parte de algumas famílias / mães em "recompensar algo feito no passado" é uma preocupação, exigência das pessoas consigo mesmas em "pagar" por aquilo que fizeram, e tais sentimentos são alimentados pelo seu passado, pelos valores adquiridos desde a infância, enfim, por sua história de vida.

Acreditamos que os acontecimentos experienciados quando criança, ao longo de sua história de vida, estimula ainda mais às mães a lutarem pelo bem estar dos seus filhos e pelos seus direitos frente ao convívio com a infecção pelo HIV.

Quanto ao tratamento medicamentoso à criança.

Desde que meu filho tava com 14 dias, quando foi descoberto o HIV nele, venho fazendo o tratamento todo certinho. [...] foi uma barra o início do tratamento, todo mês tinha que trazer meu filho pro hospital daqui, pra consultar, fazer exames, pra receber remédio pela veia. Vejo que foi uma adaptação e tanto, de todos, pra conviver com o HIV (Aladiah).

[...] me preocupo também é com as vacinas de campanha, aquela de gotinhas, a dele é especial, parece que uma tal de'Salk' (Ariel).

Sou uma mãe muito atenta, não esqueço de levar ela pra fazer os exames, faço de tudo pra dar uma vida melhor pra minha filha, pra compensar o HIV (Mikael).

É neste cenário que surge a manifestação da mãe, através do cuidado de si e do outro, no caso da criança, em busca de uma melhor qualidade de vida. Tal comportamento feminino de proteção da mãe ao filho é influenciado pelas suas vivências/ experiências quando crianças. Devem ser levadas em conta certas representações relativas ao papel materno, sendo a mãe reconhecida como a mãe protetora, a mãe competente em cuidar do filho e nele depositar sua razão de ser e existir. ${ }^{11,15}$ Quanto aos hábitos de vida (alimentação, lazer, educação, amor) evidencia-se os seguintes depoimentos.

Faço tudo pro meu filho... coloco relógio pra despertar pra dar os remédios na hora certa. Dava até pouco tempo atrás, quando ele era menor, banho nele, preparo a mochila, dou a comida, levo e trago da aula, todos os dias a mesma coisa. Me dedico a ele! (Aladiah).

Me preocupo é da minha filha estar bem alimentada, faço feijão, vitaminas... de estar com saúde e de dá carinho, amor, porque issoé tudo, mas é preciso também dar os medicamentos (Mikael).

Os relatos demonstram a importância da mãe soropositivo para o HIV, no cuidado à criança também positiva. Em face das questões vivenciadas por tais mães, faz-se necessário que os profissionais, inclusive os da enfermagem, busquem estar preparados com conhecimentos pertinentes, para além do contexto sócio-econômico e cultural, para assim desenvolverem um cuidado e uma educação em saúde, com qualidade e eficácia, bem como competências para um cuidado em enfermagem diferenciado. ${ }^{16}$

Esta condição provoca alterações na vida das pessoas não somente na estrutura e funcio- 
namento do organismo, mas também nas condições e na qualidade de vida, trazendo um alerta para a necessidade de um cuidado maior consigo mesmo, adotando ou intensificando práticas de cuidado à saúde. ${ }^{17-18}$

Neste sentido, acreditamos que as mães devem adaptar-se e reorganizar-se para enfrentar a experiência de viver e (con)viver com a infecção pelo HIV. Ressaltamos para tanto a importância da atuação da enfermagem sistematizando, desenvolvendo e avaliando o processo de cuidar à mãe e à criança, envolvidas num só contexto e, cremos que para tanto, o profissional de enfermagem deve compreender o processo de viver com o vírus HIV e, a partir de então, propor um cuidado humanizado, sem julgar, sem procurar culpados ou inocentes. ${ }^{19}$

Vale ressaltar a importância da equipe de enfermagem de compreender os sentimentos das mães frente ao diagnóstico positivo para o HIV. Estes sentimentos podem ameaçar de forma significativa a percepção que o indivíduo tem de si mesmo, ocasionando a diminuição da autoimagem. Situação esta que de certa forma poderá influenciar negativamente nas estratégias adquiridas pelas mães no convívio com a doença. ${ }^{7}$ Uma das maiores angústias das mães no convívio com a criança na mesma condição está relacionada ao momento da revelação de tal diagnóstico à criança, de como e quando fazer. ${ }^{20} \mathrm{E}$ tais angústias e receios se acentuam quando da demora para a revelação, fato que pode ser elucidado a partir dos relatos.

Desde que meu filho nasceu sempre fui de conversar muito com ele, porque alguma coisa a criança leva pra diante. [...] Quando foi descoberto o HIV no meu filho, eu já conversava com ele, dizia pra ele que era uma criança muito especial e que por isso precisaria de cuidados especiais... ele foi crescendo e ouvindo isso (Aladiah).

Não imagino ainda quando e como contar pra minha filha, só não quero é demorar mais... porque, daí ela pode achar que eu fiquei escondendo dela e ficar com raiva de mim. [...] às vezes tenho vontade de iniciar a contar quando passa alguma propaganda na televisão, mas na hora falta coragem (Mikael).

A dificuldade em revelar o diagnóstico ao seu filho abala, sobretudo, o estado emocional, causando-lhe estresse e angústia. ${ }^{7}$ Neste sentido pensamos que a abordagem à criança quanto à sua condição de soropositividade para o HIV deve ser feita precocemente. E a maneira como a mãe e/ou outro familiar vai revelar à criança é de grande importância, sendo fundamental para tanto o desenvolvimento de estratégias para falar sobre o assunto, uma vez que os acontecimentos na infância influenciam no seu futuro.

\section{CONSIDERAÇÕES FINAIS}

O desenvolvimento deste estudo sob a abordagem da História de Vida foi de fundamental relevância para identificar que muitas das experiências vivenciadas pelas mães, os valores, as histórias adquiridas ao longo da vida, influenciaram e continuam a influenciar no desenvolvimento, bem como nas escolhas das estratégias/adaptações, hoje, no convívio com a infecção pelo HIV.

Reconhecemos que a mãe com a criança com HIV positivo, além das suas características próprias, deve ser acima de tudo, fonte de amor, encorajamento e de dedicação, complementando que estes sentimentos são necessários e indispensáveis na trajetória dessas mães. Ainda neste contexto vemos que a mãe em tal condição necessita de um olhar diferenciado, mas não desigual, pois, as mães e as crianças continuam sendo as mesmas, com a diferença de que, circunstancialmente, entraram em contato com o vírus do HIV.

Podemos afirmar ainda que as estratégias desenvolvidas/adaptadas, pelas mães soropositivas para o HIV no convívio com tal diagnóstico foram influenciadas pelas suas experiências, vivências, valores, enfim pela sua história de vida. Enquanto pesquisadoras e enfermeiras, devemos estar abertas para perceber os sentimentos, atitudes e comportamentos e para que, além de esclarecermos as condições clínicas e os cuidados gerais com a pessoa, possamos estabelecer ainda vínculo, interação junto à mãe soropositivo para o HIV mediado pelo encontro. Acreditamos que o ser humano constrói sua existência por meio da cultura, sendo esta formada na família, nos grupos, na ciência, na sociedade e na política. Intervir nestas questões como profissionais de saúde nos remete à desafios de várias ordens. Mas entendemos que a superação destes desafios seja algo a ser conquistado lentamente, com empenho, empatia e aprofundamento teórico, perscrutando e escutando o que o outro tem a nos dizer, orientando suas atitudes e decisões e, sobretudo, respeitando a sua história de vida.

\section{REFERÊNCIAS}

1. Ministério da Saúde, Coordenação Nacional de DST/AIDS, Secretaria de Vigilância em saúde. Boletim Epidemiológico - DST/AIDS, Janeiro à 
Junho de 2007. Brasília: MS; 2007. [acesso em 2007 Nov 25]. Disponível em: http:/ / www.aids.gov.br/ data/Pages/LUMISE6930

2. Elsen I. Desafios de enfermagem - Marcos para a prática de enfermagem com famílias. Florianópolis (SC). Série Enfermagem, 1994.

3. Padilha MICS, Borenstein MS, Medina MS. O método da pesquisa histórica na Enfermagem. Texto Contexto Enferm. 2005 Out-Dez; 14(4):575-84.

4. Bardin L. Análise de conteúdo. Lisboa (PT): Edições 70; 1977.

5. Conselho Nacional em Saúde (Brasil). Comissão Nacional de Ética em Pesquisa com Seres Humanos. Diretrizes e normas regulamentadoras de pesquisas envolvendo seres humanos. Resolução No 196/96. Brasília; 2003.

6. Barros ML. Família e gerações. Rio de Janeiro (RJ): FGV; 2006.

7. Vieira M, Padilha MICS. O cotidiano das famílias que convivem com o HIV: um relato de experiência. Rev Esc Enferm Anna Nery. 2007 Jun; 11(2):351-7.

8. Castro LR, Organizadores. Crianças e jovens na construção da cultura. Rio de Janeiro (RJ): FAPERJ/ NAU. 2001.

9. Buchalla CM, Paiva V. Da compreensão da vulnerabilidade social ao enfoque multidisciplinar. Rev Saúde Pública. 2002 Ago; 36(4):108-16.

10. Monticelli M, Santos EKA, Erdmann AL. Being an HIV-positive mother: meanings for HIV-positive women and for professional nursing staff. Acta Paul Enferm. 2007 Jul-Set; 20(3):291-8.

11. Silva RAR, Rocha VM, Davim RMB, Torres GV. Ways of with AIDS: opinion of mother with HIV children. Rev Latino-am Enfermagem. 2008 MarAbr; 16(2):260-5.
12. Reis AL, Xavier IM. Mulher e AIDS rompendo o silêncio de adesão. Rev Brasileira Enferm. 2003 JanFev; 56(1):28-34.

13. Pietrukowicz MCLC. Apoio social e religião: uma forma de enfrentamento dos problemas de saúde [dissertação]. Rio de Janeiro (RJ): Fundação Oswaldo Cruz. Escola Nacional de Saúde Pública; 2001.

14. Maliska ICA, Padilha MICS. AIDS: A experiência da doença e a construção do itinerário terapêutico. Rev Eletr Enferm [periódico on-line]. 2007 Set-Dez [acesso em 2008 Mai 26]; 9(3):687-98. Disponível: http//:www. fen.ufg.br/revista/v9/n3/v9n3a09.htm

15. Pedro ENR, Stobaus D. Vivências e convivências de crianças portadoras de HIV / AIDS e seus familiares: implicações educacionais. Rev Paulista Enferm. 2003 Jan-Abr; 22(1):62-71.

16. Padilha MICS, Maia ARC, Vieira M, Machado C. Significados das Práticas de Não cuidados na visão de clientes Hospitalares. Rev Brasileira Enferm. 2004 NovDez; 57(6):724-8.

17. Canini SRMS, Reis RB, Pereira LA, Gir E, Pelá NTR. Qualidade de vida de indivíduos com HIV/AIDS: uma revisão de literatura. Rev Latino-am Enferm. 2004 Nov-Dez; 12(6):940-5.

18. Vieira M, Padilha MICS. O HIV e o trabalhador de enfermagem frente ao acidente com material perfurocortante. Rev Esc Enferm USP. 2008 Dez; 42(4):804-10.

19. Barroso LMM, Galvão MTG. Avaliação de atendimento prestado por profissionais de saúde à puérperas com HIV / AIDS. Texto Contexto Enferm. 2007 Jul-Set; 16(3):463-9.

20. Franco E. Como contar para uma criança que ela tem Aids. Bol. Rede Paul. de Mulheres HIV/AIDS. 1999; 9(1):16-21. 